http://jmscr.igmpublication.org/home/ ISSN (e)-2347-176x ISSN (p) 2455-0450 crossref DOI: https://dx.doi.org/10.18535/jmscr/v9i2.20

Journal Of Medical Science And Clinical Research

\title{
Clinical Manifestations and Complication Associated with Scrub Typhus with and without Eschar in a tertiary care Hospital, South India
}

\author{
Authors \\ Dr Chandana Kaspa ${ }^{1}$, Dr Abhinay Shankar Govindu \\ ${ }^{1}$ Assistant professor, Department of General Medicine, Guntur Medical College \\ ${ }^{2}$ Senior Resident, Department of General Medicine, Guntur Medical College
}

\begin{abstract}
Introduction: Scrub typhus, also known as tsutsugamushi disease, is caused by the arthropod-borne gram-negative obligately intracellular bacillus Orientia tsutsugamushi. It is a re-emerging infectious disease in India and has gained clinical importance because of its effect on multiple organ systems and progression to various complications, when not detected early and managed appropriately. The present study was conducted in a Tertiary Care Hospital in South India with an objective to study the severity of scrub typhus to presence of Eschar.

Methodology: A Cross sectional study was conducted in a Tertiary Care Hospital in South India during August 2019 to January 2020 where 200 adult patients who presented with an acute undifferentiated febrile illness and confirmed to have Scrub Typhus were included in the study.

Results: The mean age of the study participants in Eschar group was $46.68 \pm 14.69$ and the mean age among the participants without Eschar was $48.86 \pm 14.71$. Agricultural work was found to be predominant occupation in both the group $50 \%$ of the patients in Eschar group had Co-morbidities out of which 28\% had Diabetes 14\% had Hypertension, 8\% had CAD where as in the Non-Eschar group, $41 \%$ were with Co-morbidities out of which, $19 \%$ were Diabetic, $15 \%$ were Hypertensive, $7 \%$ had a history of CAD. In our study among the Eschar group 5\% Patients showed CNS manifestations and it was statistically significant when compared to non eschar group.

Conclusion: Eschar in patients with Scrub Typhus is significantly associated with a higher incidence of renal, respiratory system and CNS involvement. Hence early identification and early intervention play a key role in management of the patient.
\end{abstract}

\section{Introduction}

Scrub typhus is a serious public health problem in the Asia-Pacific area including, but not limited to, Korea, Japan, China, Taiwan, India, Indonesia, Thailand, Sri Lanka, and the Philippines. ${ }^{1}$ It threatens one billion people globally, and causes illness in one million people each year ${ }^{2}$. Scrub typhus, also known as tsutsugamushi disease, is caused by the arthropod-borne gram-negative obligately intracellular bacillus Orientia tsutsugamushi ${ }^{3}$. It is a re-emerging infectious disease in India and has gained clinical importance because of its effect on multiple organ systems and progression to various complications, when not detected early and managed appropriately. ${ }^{4}$

Approximately 5 to 14 days after being bitten by an infected vector, a Leptotrombidium mite, 
patients begin to exhibit manifestations of infection such as non-specific flu-like symptoms, fever, rash, eschar at the bite site, headache, myalgia, cough, generalized lymphadenopathy, nausea, vomiting, and abdominal pain ${ }^{5}$.

An eschar at the site of chigger feeding is a classic clinical feature of scrub typhus. It begins as a papule at the site of chigger feeding and then ulcerates and forms a black crust like a skin burn from a cigarette. When present, it occurs prior to the onset of fever and other symptoms ${ }^{6}$

In male patients, eschars are primarily within 30 $\mathrm{cm}$ below the umbilicus. The other common locations are lower extremities and anterior chest. There is a different pattern in female patients, whose anterior chest, head and neck are the most prevalent areas $^{7}$

Severe complications such as multiorgan failure occur in some cases. The severe multiorgan manifestations include jaundice, acute renal failure, pneumonitis, acute respiratory distress syndrome (ARDS), myocarditis, septic shock, meningoencephalitis, pericarditis, and disseminated intravascular coagulation Meningitis and/or encephalitis can develop in severe illness, causing patients to become agitated, delirious or even have seizures. Focal neurological signs are rare but have been known to occur. The case fatality can be up to $30-70 \%$ if no appropriate treatment is received while the median case fatality rate for untreated patients is $6 \%$ and for treated patient is $1.4 \%$ Therefore, development of effective measures to treat, control and prevent the disease is a critical public health issue. ${ }^{1}$

The present study was conducted in a Tertiary Care Hospital in South India with an objective to study the severity of scrub typhus to presence of Eschar and also tofind out the differences between Scrub Typhus patients with eschar and without eschar in relation to clinical features, degree of organ involvement.

\section{Objectives of the study}

1. To study the different clinical manifestation and complication associated with scrub typhus with and without Eschar.

\section{Materials and Methods}

ACross sectional study was conducted in a Tertiary Care Hospital in South India during August 2019 to January 2020 where 200 adult patients who presented with an acute undifferentiated febrile illness and confirmed to have Scrub Typhus were included in the study. Scrub Typhus was diagnosed in patients presenting with an acute febrile illness of $<14$ days duration and a positive Scrub IgM ELISA (In Bios International, Inc., Seattle, USA) with other aetiologies being negative. Other infectious aetiologies for acute febrile illness, like malaria, enteric fever, dengue fever and leptospirosis were ruled out by appropriate tests.

The patients with ST were divided into two groups i.e. 100 in each group based on the presence or absence of eschar. Clinical features, organ involvement and outcome in both groups were compared to observe for clinical and statistical significance.

\section{Statistical Analysis}

Data tabulation using Microsoft Excel 2013 and statistically analysis was done SPSS version 16. Descriptive statistics include Mean, standard deviation, frequencies, and percentages were calculated. Unpaired $\mathrm{T}$ test was used to compare the parametric data among the 2 groups. Chisquare test was used for non-parametric data. At $95 \%$ confidence interval, $\mathrm{P}$ value of $<0.05$ was statistically significant.

\section{Results}

In the present study, the mean age of the study participants in Eschar group was $46.68 \pm 14.69$ and the mean age among the participants without Eschar was $48.86 \pm 14.71$. There was no statistically significant difference observed between the two groups as the $\mathrm{p}$ value calculated to be $>0.05$. 
Among the Eschar group, majority i.e. 51\% were female and in the Non-Eschar group, majority were Male i.e. $62 \%$.

Agricultural work was found to be predominant occupation in both the group as $65 \%$ of the patients were into Agricultural work and 35\% were House wife in the Eschar group whereas in the Non Eschar group, 53.5\% were into Agricultural work, $33 \%$ were House wife.
$50 \%$ of the patients in Eschar group had Comorbidities out of which $28 \%$ had Diabetes $14 \%$ had Hypertension, $8 \%$ had CAD where as in the Non-Eschar group, $41 \%$ were with Co-morbidities out of which, $19 \%$ were Diabetic, $15 \%$ were Hypertensive, $7 \%$ had a history of CAD.

In the present study, fever with chills, abdominal pain, Breathlessness, seizure and overt bleeding showed a statistically significant difference as the $\mathrm{p}$ value calculated to be $<0.05$. (Table 1 )

Table 1: Clinical Presentation

\begin{tabular}{|c|c|c|c|c|c|c|c|}
\hline \multirow{2}{*}{ Variable } & \multirow{2}{*}{ Group } & \multicolumn{2}{|c|}{ With Eschar } & \multicolumn{2}{|c|}{ Without Eschar } & \multirow[t]{2}{*}{ Chi-square value } & \multirow[t]{2}{*}{$P$ value } \\
\hline & & $\mathrm{N}$ & $\%$ & $\mathrm{n}$ & $\%$ & & \\
\hline \multirow{2}{*}{ Fever with Chills } & Yes & 83 & 83 & 66 & 66 & \multirow[t]{2}{*}{7.61} & \multirow[t]{2}{*}{$<0.05^{*}$} \\
\hline & No & 17 & 17 & 34 & 34 & & \\
\hline \multirow{2}{*}{ Myalgia } & Yes & 57 & 57 & 45 & 45 & \multirow[t]{2}{*}{2.88} & \multirow[t]{2}{*}{$>0.05$} \\
\hline & No & 43 & 43 & 55 & 55 & & \\
\hline \multirow{2}{*}{ Headache } & Yes & 52 & 52 & 40 & 40 & \multirow[t]{2}{*}{2.90} & \multirow[t]{2}{*}{$>0.05$} \\
\hline & No & 48 & 48 & 60 & 60 & & \\
\hline \multirow{2}{*}{ Vomiting } & Yes & 50 & 50 & 39 & 39 & \multirow[t]{2}{*}{2.45} & \multirow[t]{2}{*}{$>0.05$} \\
\hline & No & 50 & 50 & 61 & 61 & & \\
\hline \multirow{2}{*}{ Abdominal Pain } & Yes & 50 & 50 & 31 & 31 & \multirow[t]{2}{*}{7.49} & \multirow[t]{2}{*}{$<0.05^{*}$} \\
\hline & No & 50 & 50 & 69 & 69 & & \\
\hline \multirow{2}{*}{ Breathlessness } & Yes & 41 & 41 & 2 & 2 & \multirow[t]{2}{*}{45.1} & \multirow[t]{2}{*}{$<0.05^{*}$} \\
\hline & No & 59 & 59 & 98 & 98 & & \\
\hline \multirow{2}{*}{ Cough } & Yes & 32 & 32 & 30 & 30 & \multirow[t]{2}{*}{0.93} & \multirow[t]{2}{*}{$>0.05$} \\
\hline & No & 68 & 68 & 70 & 70 & & \\
\hline \multirow{2}{*}{ Altered Sensorium } & Yes & 15 & 15 & 9 & 9 & \multirow[t]{2}{*}{1.70} & \multirow[t]{2}{*}{$>0.05$} \\
\hline & No & 85 & 85 & 91 & 91 & & \\
\hline \multirow{2}{*}{ Seizure } & Yes & 5 & 5 & 0 & 0 & \multirow[t]{2}{*}{5.13} & \multirow[t]{2}{*}{$<0.05^{*}$} \\
\hline & No & 95 & 95 & 100 & 100 & & \\
\hline \multirow{2}{*}{ Overt bleeding } & Yes & 5 & 5 & 0 & 0 & 5.13 & $<0.05^{*}$ \\
\hline & No & 95 & 95 & 100 & 100 & & \\
\hline
\end{tabular}

A significant difference was observed between the two groups $(\mathrm{p}<0.05)$ with Laboratory parameters include $\mathrm{Hb}$ gm\%, WBC count, Neutrophils,
Platelet count, Serum Creatinine, Urea, CPK, Albumin, SGOT, SGPT, ALP.(Table 2)

Table 2: Biochemical Parameters

\begin{tabular}{|l|c|c|c|c|c|c|}
\hline \multirow{2}{*}{ Variable } & \multicolumn{2}{|c|}{ With Eschar } & \multicolumn{2}{c|}{ Without Eschar } & \multirow{2}{*}{ T value } & \multirow{2}{*}{ P Value } \\
\cline { 2 - 5 } & Mean & SD & Mean & SD & & \\
\hline Hb & 12.13 & 2.94 & 10.98 & 2.99 & 2.74 & $<0.05^{*}$ \\
\hline WBC count & 10457.00 & 1118.33 & 8119.40 & 2140.09 & 9.68 & $<0.05^{*}$ \\
\hline Neutrophils & 69.12 & 9.31 & 64.17 & 9.09 & 3.80 & $<0.05^{*}$ \\
\hline Platelet count & 93295.00 & 15281.13 & 103410.00 & 24909.23 & 3.46 & $<0.05^{*}$ \\
\hline creatinine & 1.27 & 0.36 & 1.14 & 0.32 & 2.69 & $<0.05^{*}$ \\
\hline urea & 39.79 & 12.25 & 28.60 & 6.87 & 7.96 & $<0.05^{*}$ \\
\hline CPK & 131.12 & 73.20 & 207.70 & 102.56 & 6.07 & $<0.05^{*}$ \\
\hline Bicarbonate & 18.72 & 4.03 & 18.88 & 4.49 & 0.26 & $>0.05$ \\
\hline Total Bilirubin & 1.35 & 0.77 & 1.55 & 0.83 & 1.76 & $>0.05$ \\
\hline Total protein & 6.82 & 0.79 & 6.94 & 0.90 & 1.01 & $>0.05$ \\
\hline Albumin & 3.55 & 0.81 & 3.07 & 0.55 & 4.90 & $<0.05^{*}$ \\
\hline SGOT & 429.66 & 229.65 & 160.47 & 80.31 & 11.06 & $<0.05^{*}$ \\
\hline SGPT & 55.71 & 26.36 & 93.57 & 44.98 & 7.26 & $<0.05^{*}$ \\
\hline ALP & 128.64 & 78.28 & 146.24 & 42.24 & 1.97 & $<0.05^{*}$ \\
\hline
\end{tabular}


Data with respect to systemic involvement between Eschar group vs Non Eschar group, Hematologic involvement ( $13 \%$ vs $10 \%, \mathrm{p}>0.05$ ), Renal involvement $(25 \%$ vs $17 \%, \mathrm{p}>0.05)$, CVS involvement $(14 \%$ vs $10 \%, \mathrm{p}>0.05)$, CNS involvement $(5 \%$ vs $0 \%, \mathrm{p}<0.05)$, Hepatic involvement $(6 \%$ vs $4 \%, \quad \mathrm{p}>0.05), \quad$ GI involvement ( $2 \%$ vs $17 \%, \mathrm{p}<0.05)$, Respiratory system involvement ( $32 \%$ vs $18 \%, \mathrm{p}<0.05)$ (Table 3)

Table 3: Systemic Involvement

\begin{tabular}{|c|c|c|c|c|c|c|}
\hline \multirow{2}{*}{ Variable } & \multirow{2}{*}{ Group } & \multicolumn{2}{|c|}{ With Eschar } & \multicolumn{2}{|c|}{ Without Eschar } & \multirow[t]{2}{*}{$P$ value } \\
\hline & & $\mathrm{n}$ & $\%$ & $\mathrm{~N}$ & $\%$ & \\
\hline \multirow{2}{*}{ Hematologic involvement } & Yes & 13 & 13 & 10 & 10 & \multirow[t]{2}{*}{$>0.05$} \\
\hline & No & 87 & 87 & 90 & 90 & \\
\hline \multirow{2}{*}{ Renal Involvement } & Yes & 25 & 25 & 17 & 17 & \multirow[t]{2}{*}{$>0.05$} \\
\hline & No & 75 & 75 & 83 & 83 & \\
\hline \multirow{2}{*}{ CVS involvement } & Yes & 14 & 14 & 10 & 10 & \multirow[t]{2}{*}{$>0.05$} \\
\hline & No & 86 & 86 & 90 & 90 & \\
\hline \multirow{2}{*}{ CNS involvement } & Yes & 5 & 5 & 0 & 0 & \multirow[t]{2}{*}{$<0.05^{*}$} \\
\hline & No & 95 & 95 & 100 & 100 & \\
\hline \multirow{2}{*}{ Hepatic involvement } & Yes & 6 & 6 & 4 & 4 & \multirow[t]{2}{*}{$>0.05$} \\
\hline & No & 94 & 94 & 96 & 96 & \\
\hline \multirow{2}{*}{ GI involvement } & Yes & 2 & 2 & 17 & 17 & \multirow[t]{2}{*}{$<0.05^{*}$} \\
\hline & No & 98 & 98 & 83 & 83 & \\
\hline \multirow{2}{*}{ RS involvement } & Yes & 32 & 32 & 18 & 18 & \multirow[t]{2}{*}{$<0.05^{*}$} \\
\hline & No & 68 & 68 & 82 & 82 & \\
\hline
\end{tabular}

\section{Discussion}

In the present study, the mean age of the Eschar group was $46.68 \pm 14.69$ and non Eschar group was $48.86 \pm 14.71$. Study by Premraj et $\mathrm{al}^{4}$, the mean age of the patients was $39.6 \pm 20.5 \mathrm{yr}$ (mean \pm SD). Nadjm et $\mathrm{al}^{8}$ in their study reported that Peak incidence of scrub typhus was reported to be in the fifth decade of life. Varghese et $\mathrm{al}^{9}$ study reported that the mean age of patients was $45 \pm 15$ years.

Nadjm et $\mathrm{al}^{8}$ in their study reported that occupation of majority of the patients with scrub typhus was farming $(140 / 251 ; 55.7 \%)$ which is similar to the present study. Agricultural laborers were predominant occupation in study by Varghese et $\mathrm{al}^{9}$ which is similar to present study.

In the present study, Fever with chills, Headache were the most common presenting complaints by the majority of the patients which is similar to study conducted by Jamil et $\mathrm{al}^{10}$ where the commonest presentation was an acute febrile illness with severe headache $(94.91 \%)$, which is global and throbbing in nature.

Park et $\mathrm{al}^{11}$ reported that The independent risk factors were old age and underlying chronic diseases like DM and other less frequent diseases. This corroborates our clinical impression that elderly patients fromrural areas with underlying chronic diseases had more severe clinical presentations and prolonged morbidity.

In our study Regarding the clinical severity of scrub typhus, Eschar group vs Non Eschar group, Hematologic involvement (13\% vs $10 \%, \mathrm{p}>0.05$ ), CNS involvement ( $5 \%$ vs $0 \%, \mathrm{p}<0.05$ ), Hepatic involvement $(6 \%$ vs $4 \%, \quad \mathrm{p}>0.05), \quad$ GI involvement ( $2 \%$ vs $17 \%, \mathrm{p}<0.05$ ), Respiratory system involvement $(32 \%$ vs $18 \%, \mathrm{p}<0.05)$. study by Park et $\mathrm{al}^{11}$ showed similar results where there were16 cases of severe complications (10.5\%). Respiratory complications (7.8\%), CNS complications (5.9\%), cardiac complications (2\%), and septic shock (1.3\%) were observed.

In a study by Shaikh et al ${ }^{12}$ Acute renal failure was significantly more among patients with aneschar $(18.1 \%)$ as against $5.7 \%$ in those without an eschar. Other studies from India reported a 12$33 \%$ incidence of renal failure ${ }^{13}$. Previous studies from India show an incidence of acute respiratory distress syndrome of $8-25 \%$ with majority of them requiring invasive ventilation. ${ }^{14}$ Tsay and Chang 
reported no association between the presence of an eschar and pulmonary involvement. ${ }^{15}$

In a study by Pai et $\mathrm{al}^{16} \mathrm{CNS}$ manifestations of Scrub Typhus infection occurs in $12.5-26 \%$ of affected patients. In our study among the Eschar group 5 Patients showed CNS manifestations and it was statistically significant when compared to non eschar group.

\section{References}

1. Xu G, Walker DH, Jupiter D, Melby PC, Arcari CM. A review of the global epidemiology of scrub typhus. PLoS Negl Trop Dis. 2017 Nov 3;11(11):e0006062.

2. Kelly DJ, Fuerst PA, Ching W-M, Richards AL. Scrub typhus: the geographic distribution of phenotypic and genotypic variants of Orientia tsutsugamushi. Clin Infect Dis Off Publ Infect Dis Soc Am. 2009 Mar 15;48 Suppl 3:S203-230.

3. Valbuena G, Walker DH. Approaches to vaccines against Orientia tsutsugamushi. Front Cell Infect Microbiol. 2012;2:170.

4. Premraj SS, Mayilananthi K, Krishnan D, Padmanabhan K, Rajasekaran D. Clinical profile and risk factors associated with severe scrub typhus infection among non-ICU patients in semi-urban south India. J Vector Borne Dis. 2018 Jan 1;55(1):47.

5. Jeong YJ, Kim S, Wook YD, Lee JW, Kim K-I, Lee SH. Scrub typhus: clinical, pathologic, and imaging findings. Radiogr Rev Publ Radiol Soc N Am Inc. 2007 Feb;27(1):161-72.

6. Mahajan SK. Scrub typhus. J Assoc Physicians India. 2005 Nov;53:954-8.

7. Kim D-M, Won KJ, Park CY, Yu KD, Kim HS, Yang TY, et al. Distribution of eschars on the body of scrub typhus patients: a prospective study. Am J Trop Med Hyg. 2007 May;76(5):806-9.

8. Nadjm B, Thuy PT, Trang VD, Dang Ha L, Kinh NV, Wertheim HF. Scrub typhus in the northern provinces of Vietnam: an observational study of admissions to a national referral hospital. Trans R Soc Trop Med Hyg. 2014 Nov;108(11):739-40.

9. Varghese GM, Janardhanan J, Trowbridge P, Peter JV, Prakash JAJ, Sathyendra S, et al. Scrub typhus in South India: clinical and laboratory manifestations, genetic variability, and outcome. Int J Infect Dis. 2013 Nov;17(11):e981-7.

10. Karanth SS, Marupudi KC, Sama VPR, Gupta A, Ballal K, Kamath A. Predictors of severity of scrub typhus in the Indian subcontinent. Asian Pac J Trop Dis. 2014 Sep 1;4:S674-8.

11. Park S-W, Lee C-S, Lee CK, Kwak YG, Moon C, Kim B-N, et al. Severity Predictors in Eschar-Positive Scrub Typhus and Role of Serum Osteopontin. Am J Trop Med Hyg. 2011 Nov 1;85(5):924-30.

12. Shaikh IAA, Kundavaram PPA, Mitra S, Jayakaran JAJ, Trinity P, Varghese GM. Does the presence of an eschar correlate with severity of scrub typhus infection? Indian J Med Sci. 2017 Mar 28;69(1):36-9.

13. Narvencar KP, Rodrigues S, Nevrekar RP, Dias L, Dias A, Vaz M, et al. Scrub typhus in patients reporting with acute febrile illness at a tertiary health care institution in Goa. Indian J Med Res. 2012 Dec 1;136(6):1020.

14. Wang C-C, Liu S-F, Liu J-W, Chung Y-H, Su $\mathrm{M}-\mathrm{C}$, Lin M-C. Acute respiratory distress syndrome in scrub typhus. Am J Trop Med Hyg. 2007 Jun;76(6):1148-52.

15. Tsay RW, Chang FY. Acute respiratory distress syndrome in scrub typhus. QJM Mon J Assoc Physicians. 2002 Feb;95(2):126-8.

16. Pai H, Sohn S, Seong Y, Kee S, Chang WH, Choe KW. Central nervous system involvement in patients with scrub typhus. Clin Infect Dis Off Publ Infect Dis Soc Am. 1997 Mar;24(3):436-40. 